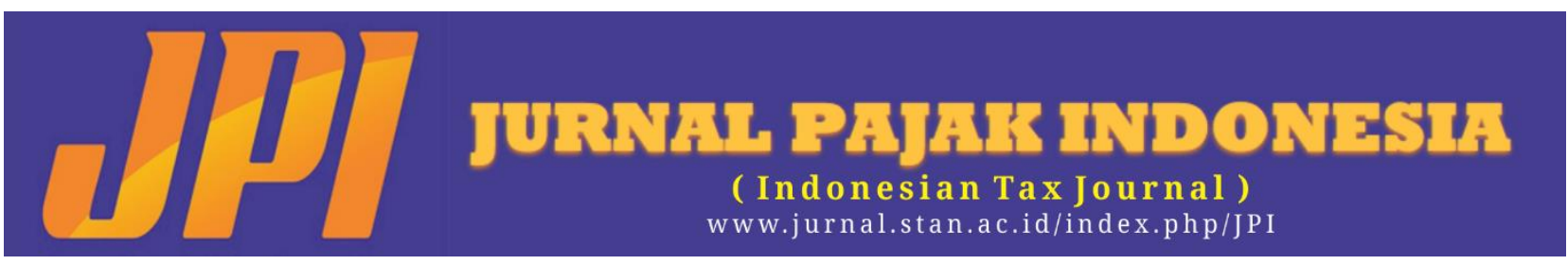

\title{
PERLUKAH REVERSE TOBIN TAX DI INDONESIA?
}

\author{
Sulfan \\ Politeknik Keuangan Negara STAN
}

Alamat Korespondensi: sulfan76@pkn.stan.ac.id

\section{INFORMASI ARTIKEL}

Diterima Pertama

[18082019]

Dinyatakan Diterima

[09092019]

KATA KUNCI:

Tobin Tax, Reverse Tobin Tax, Investasi, Insentif

KLASIFIKASI JEL:

$\mathrm{H} 20$

\begin{abstract}
Foreign investment in Indonesia is dominated by portfolio investment compared to foreign direct investment (FDI). Since the end of 2017, the proportion of foreign portfolio investment is more than $70 \%$ in the form of stocks and bonds and tends to be short-term so that capital outflows can sudden reversal. The impact of financial markets is shaken and the exchange rate falls. One of the ideas to hold foreign portfolio investment in Indonesia is to implement the Reserved Tobin Tax (RTT) policy. In contrast to Tobin Tax that tax portfolio transactions, RTT provides tax incentives for foreign portfolios that last for a certain period in Indonesia. Based on the results of the analysis, there are policies that are almost similar to the RTT that have been implemented in Indonesia. Tax income Borne by Government on interest Government Securities (SBN) and Final Income Tax until rate 0\% on interest Deposit / Savings in Dollars US whose funds are sourced from Export. Difficulties in determining the amount of tax incentives, cluster investment portfolio types, recording and monitoring of holding periods, third parties appointed by the government, and supervision from tax authorities, indicate that the government has not yet taken RTT policy.
\end{abstract}

\section{ABSTRAK}

Investasi asing di Indonesia didominasi investasi portofolio dibandingkan foreign direct investment (FDI). Sejak akhir 2017, proporsi investasi portofolio asing lebih dari $70 \%$ berbentuk saham dan obligasi dan cenderung berjangka pendek sehingga arus modal keluar bisa tibatiba terjadi (sudden reversal). Dampaknya pasar keuangan tergoncang dan nilai tukar mata uang jatuh. Salah satu ide menahan investasi portofolio asing agar betah di Indonesia adalah diterapkannya kebijakan Reserved Tobin Tax (RTT). Berkebalikan dengan Tobin Tax yang memajaki transaksi portofolio, RTT memberikan insentif pajak atas portofolio asing yang bertahan untuk jangka waktu tertentu di Indonesia. Berdasarkan hasil analisis, terdapat kebijakan yang hampir mirip dengan RTT yang telah diterapkan di Indonesia. PPh Ditanggung Pemerintah atas bunga Surat Berharga Negara (SBN) dan pemotongan PPh Final lebih rendah bahkan $0 \%$ atas bunga Deposito/Tabungan dalam mata uang Dollar Amerika Serikat yang dananya bersumber dari Devisa Hasil Ekspor (DHE). Kesulitan penentuan besaran insentif pajak, klaster jenis investasi portofolio, pencatatan dan pengawasan holding period, pihak ketiga yang ditunjuk pemerintah, dan pengawasan dari otoritas pajak, mengindikasikan belum saatnya pemerintah mengambil kebijakan RTT. 


\section{PENDAHULUAN}

Indonesia menganut kebijakan perekonomian terbuka. Penanaman modal asing, baik dalam bentuk investasi langsung (Foreign Direct Investment-FDI) dan investasi portfolio (saham, obligasi, surat utang negara dan derivatif lainnya) menjadi bagian penting dalam perekonomian Indonesia. Faktor perekonomian global dan kebutuhan investasi di dalam negeri mempengaruhi perkembangan investasi asing di Indonesia, dan lalu lintas investasi asing akan berpengaruh pada kondisi perekonomian karena melibatkan permintaan dan penawaran mata uang asing (valuta asing) yang berhubungan dengan tingkat nilai tukar mata uang. Dalam 5 tahun terakhir (Gambar 1), Indonesia mengalami defisit transaksi berjalan (current account deficit-CAD) berkisar di angka US\$16 miliar sampai dengan US\$26 miliar. Pada tahun 2018 sampai dengan triwulan III, CAD Indonesia sebesar US\$22 miliar. Karena terjadi CAD tersebut, diharapkan terus terjadi surplus di neraca modal dan finansial (capital and financial account) untuk mengurangi besaran CAD di neraca pembayaran Indonesia.

Investasi portfolio dibandingkan dengan FDI, mempunyai karakteristik tersendiri yaitu dapat dinegosiasikan, dirancang untuk diperdagangkan di pasar yang terorganisir, dapat dibeli dan dijual, efisien dan fleksibel serta menawarkan berbagai risiko dan tingkat pengembalian ${ }^{1}$. Dengan sifat yang lebih fleksibel dan dapat diperdagangkan, mobilitas investasi portfolio asing dapat memunculkan volatilitas nilai tukar mata uang yang pada akhirnya berdampak pada stabilitas makroekonomi suatu negara. Di Indonesia, pengaturan FDI mengacu pada Undang-Undang Nomor 25 Tahun 2007 tentang Penanaman Modal (UU 25/2007), sedangkan investasi portfolio mengacu pada UndangUndang 8 Tahun 1995 tentang Pasar Modal (UU 8/1995) dan Undang-Undang Nomor 24 Tahun 2002 tentang Surat Utang Negara (UU 24/2002).

Gambar 1: Neraca Pembayaran Indonesia, 2014-2018 (Triwulan III) - (dalam miliar US\$)

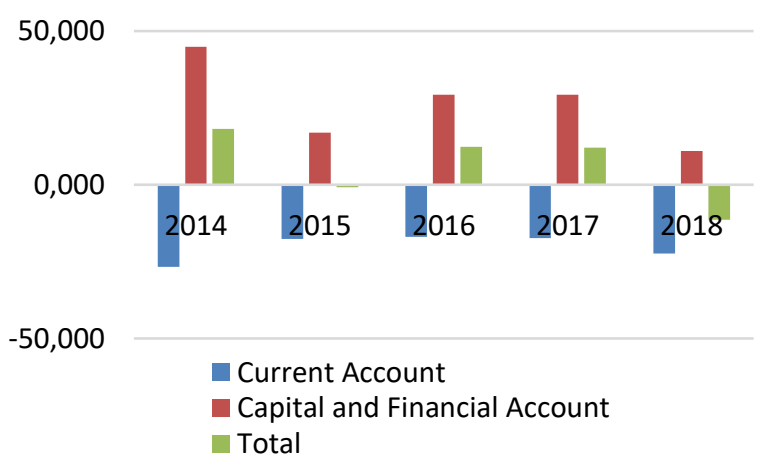

Sumber: https://www.bi.go.id/en/publikasi/neracapembayaran/Default.aspx (diolah)

\footnotetext{
${ }^{1}$ https://www.imf.org/external/region/tlm/rr/pdf/Jan11.pdf 2 https://nasional.kontan.co.id/news/kebijakan-reversetobin-tax-masih-dalam-proses-pengkajian 3https://ekonomi.kompas.com/read/2018/09/03/171242326 /bi-rating-bbb-dari-fitch-tegaskan-indonesia-layak-investasi, https://katadata.co.id/berita/2018/09/04/peringkat-layak-
}

Investasi portofolio masih menjadi pendongkrak surplus transaksi modal dan finansial. Seiring dengan berkurangnya tekanan sentimen global, arus masuk alias inflow investasi portofolio naik signifikan yakni mencapai US\$11,47 miliar di triwulan IV-2018. Sedangkan capital inflow pada tiga triwulan sebelumnya terhitung tipis. Pada triwulan I-2018 tercatat US\$0,29 miliar. Sedangkan pada triwulan II2018 tercatat US\$1,35 miliar, naik tipis pada triwulan III2018 tercatat US\$1,39 miliar. Perkembangan jumlah investasi potfolio di Indonesia Tahun 2018 disajikan dalam Gambar 2. Hal ini sejalan dengan sentimen global yang kuat pada awal hingga pertengahan tahun $2018^{2}$. Di samping itu, kenaikan investasi di Indonesia juga didukung oleh predikat layak investasi (investment grade) yang diberikan oleh tiga lembaga pemeringkat investasi internasional yaitu Fitch Ratings, Standard and Poors (S\&P) dan Moody's Investor Service ${ }^{3}$. Predikat tersebut diberikan karena Indonesia dianggap memiliki kerangka kebijakan kredibel dan efektif yang dinilai kondusif bagi stabilitas makroekonomi, atau dengan kata lain, perekonomian Indonesia tetap dalam kondisi yang baik dan stabil.

Gambar 2: Investasi Portfolio di Indonesia, tahun 2018

(dalam miliar US\$)

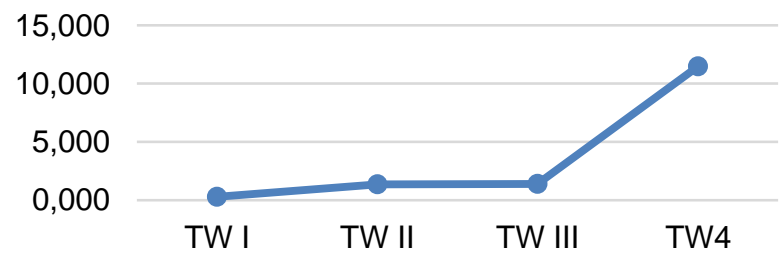

Sumber: https://nasional.kontan.co.id/news/kebijakan -reverse-tobin-tax-masih-dalam-proses-pengkajian (diolah)

Kondisi ini menjelaskan bahwa investasi portofolio cenderung berjangka pendek, sehingga mudah terjadi arus keluar modal. Untuk menahan cepatnya arus keluar, pada akhir Januari lalu pemerintah mengaku tengah mengkaji kebijakan insentif pajak untuk aliran modal asing yang disimpan di pasar keuangan alias Reverse Tobin Tax (RTT) ${ }^{4}$. RTT sebagai salah satu langkah yang bisa diterapkan pemerintah untuk meminimalkan risiko gejolak di pasar keuangan domestik dan nilai tukar rupiah. Dalam RTT, pemerintah memberikan insentif pajak jika investor

investasi-tanda-ekonomi-indonesia-baik, dan https://ekonomi.kompas.com/read/2018/04/13/103000226/ bi--kenaikan-rating-oleh-moody-s-prestasi-besar-untukindonesia

4 ibid 
melakukan re-investasi keuntungannya untuk jangka panjang 5 .

Kebijakan tersebut merupakan kebalikan dari kebijakan Tobin Tax yang mengenakan pajak pada arus modal jangka pendek. Namun keduanya memiliki ide yang sama yaitu mencegah adanya arus modal keluar dalam jangka pendek (sudden reversal) yang dapat mengakibatkan pasar keuangan terguncang, nilai tukar jatuh, terutama di negara-negara yang defisit transaksi berjalannya dibiayai oleh portfolio (aliran modal asing ke pasar modal), termasuk Indonesia.

Muhammad Chatib Basri, mantan Menteri Keuangan RI menyatakan bahwa ide mengenai RTT erat dihubungkan dengan terjadinya $C A D$, yang merupakan kondisi dimana angka pertumbungan impor lebih tinggi dibanding dengan angka pertumbuhan ekspor. Sebenarnya, CAD tidak terlalu membahayakan perekonomian asalkan dibiayai oleh investasi asing langsung (foreign direct investment-FDI) di sektor ekspor terutama manufaktur, dan bukan investasi portofolio. Pembiayaan eksternal dalam bentuk portofolio terutama jangka pendek yang menjadi penyebab volatilitas. Kondisi di Indonesia, sekitar 25 persen dari pembiayaan defisit anggaran pemerintah adalah berupa obligasi global (global bonds, pemegangnya investor asing), sisanya 75 persen obligasi rupiah. Namun, 35-40 persen pemegang obligasi rupiah adalah investor asing ${ }^{6}$.

Menteri Keuangan Sri Mulyani Indrawati mengatakan bahwa seluruh dunia telah melihat bahwa lalu lintas devisa yang terlalu bebas bisa berdampak positif, tetapi juga bisa mengganggu (disruptive). Kebijakan untuk meredam gangguan (salah satunya RTT) merupakan suatu kebijakan yang dibenarkan. Yang menjadi permasalahan adalah lebih ke desain dan dampak-dampak yang terkait, daripada perlu atau tidaknya kebijakan tersebut ${ }^{7}$. Negara-negara berkembang seperti Indonesia cukup rentan terhadap aliran modal jangka pendek. Hal tersebut, tentu akan mengancam stabilitas. Esensi Tobin Tax (maupun RTT) adalah bagaimana untuk tidak menciptakan ketidakstabilan tetapi tetap mendapatkan manfaat aliran modal tersebut ${ }^{8}$. Para pengambil kebijakan perlu memikirkan reaksi investor yang bakal muncul. Yang lebih penting adalah tujuan dan arah keberpihakan pemerintah serta seberapa siap pemerintah mengoptimalkan penerapan kebijakan tersebut ${ }^{9}$.

Melihat kondisi pasar modal Indonesia yang masih didominasi investor asing (kepemilikan asing atas SBN mencapai 38\%), Tobin Tax sulit diterapkan.

\footnotetext{
5 Basri, Muhammad Chatib, This Time Is (Not) Different, laman facebook akun Muhammad Chatib Basri Penuh, $7 / 1 / 2019$

${ }^{6}$ http://uiupdate.ui.ac.id/article/muhammad-chatib-basrimembahas-kewaspadaan-terhadap-perekonomian-indonesia ${ }^{7}$ https://katadata.co.id/berita/2019/01/10/ide-reversetobin-tax-untuk-pertahankan-dana-asing-ditanggapiberagam,

8 https://www.cnbcindonesia.com/market/2019010816195217-49601/kajian-lagi-sri-mulyani-pertimbangkan-tobin-taxmodal-asing,
}

Sebaliknya, RTT lebih cocok diterapkan untuk menahan investasi tersebut tetap dalam negeri untuk jangka waktu panjang ${ }^{10}$. Kebijakan RTT dapat diterapkan secara fleksibel. Ketika arus modal cukup kuat, maka pajak dapat normalisasi. Di sisi lain, meskipun RTT diperlukan untuk menarik dana asing lebih besar, namun, kebijakan tersebut belum tepat jika diterapkan dalam kondisi pasar yang bergejolak karena investor tidak mempunyai perspektif jangka panjang ${ }^{11}$.

Di samping hal-hal tersebut di atas, terungkap pula bahwa munculnya ide RTT dikaitkan dengan akan berakhirnya masa tahan (holding period) dana repatriasi pengampunan pajak yang berjumlah sekitar Rp146 triliun. Masa tahan dana repatriasi selama 3 tahun akan berakhir tahun ini menimbulkan kekhawatiran akan larinya dana-dana tersebut ke luar negeri. Namun demikian, Menteri Keuangan Sri Mulyani meyakini bahwa dana tersebut tidak akan meninggalkan Indonesia. Hal tersebut karena situasi ekonomi internal Indonesia masih sangat baik, pertumbuhannya tinggi dengan inflasi yang terjaga, juga memberikan return of investment yang relatif baik dibanding negara lain. Terkait hal ini, pemerintah melalui DJP terus memantau dana repatriasi tersebut serta terus berkomunikasi dengan OJK dan BI tentang langkah-langkah yang perlu dilakukan terkait perpanjangan dana repatriasi di dalam instrumen investasi ${ }^{12}$.

Perkembangan terakhir, kajian kebijakan RTT secara umum masih belum menjadi fokus utama, karena pemerintah memilih fokus terlebih dahulu ke penyusunan peraturan pelaksanaan PP Nomor 1 Tahun 2019 dalam bentuk pengurangan tarif pajak deposito untuk devisa hasil ekspor (DHE). Pengurangan tarif pajak untuk deposito DHE disebut sebagai salah satu contoh RTT. Selain itu, RTT lebih terkait dengan teknikal pasar modal ${ }^{13}$.

Berdasarkan uraian di atas, untuk memperbaiki struktur transaksi modal dan finansial, pemerintah perlu membuat bauran kebijakan insentif dan disinsentif. Insentif berupa pengurangan pajak untuk keuntungan yang direinvestasi jangka panjang, sedangkan jika laba hasil dividen atau capital gain dikonversi ke valuta asing maka akan dikenakan pajak. Dengan kata lain, perlu dikaji kemungkinan kebijakan Reverse Tobin $\operatorname{Tax}^{14}$.

\section{METODE PENELITIAN}

Penelitian ini menggunakan cara pandang realitas keadaan sebagai sesuatu yang utuh, kompleks,

\footnotetext{
${ }^{9}$ https://www.cnbcindonesia.com/opini/20180816200235-

14-29048/depresiasi-rupiah-dan-relevansi-tobin-tax,

${ }^{10}$ https://nasional.kontan.co.id/news/tobin-tax-belumcocok-untuk-pasar-indonesia,

11 ibid

${ }^{12}$ https://ekonomi.kompas.com/read/2019/01/29/15485462

6/sri-mulyani-dana-repatriasi-tak-lari-lagi-ke-luar-negeri,

13 https://nasional.kontan.co.id/news/kebijakan-reversetobin-tax-masih-dalam-proses-pengkajian,

14 Ibid
} 
dinamis, dan hubungan gejalanya bersifat interaktif atau reciprocal. Paradigma penelitian sedemikian rupa sering disebut sebagai paradigma interpretif dan konstruktif atau paradigma post-positivism. Adapun pendekatan penelitian yang mengacu atau sesuai dengan paradigma penelitian tersebut adalah metode pendekatan kualitatif. Tehnik pengumpulan data dilakukan melalui pengumpulan data dan/atau informasi yang relevan dengan tujuan penulisan.

\section{TINJAUAN LITERATUR DAN TEORI}

Kajian ide pengenaan Reverse Tobin Tax berangkat dari teori Tobin Tax. Berdasarkan literatur, Tobin Tax adalah jenis pajak yang dipolulerkan oleh James Tobin (1918-2002). James Tobin adalah peraih Nobel Prize in Economics pada tahun 1981 untuk analisisnya mengenai pasar modal dan hubungannya dengan keputusan pengeluaran, tenaga kerja, produksi dan harga. Ide pajak ini sederhana yaitu dengan "throwing some sand in the well-greased wheels of international finance". Dalam praktiknya, Tobin mengusulkan pengenaan pajak atas transaksi valuta asing guna meredam arus hot money agar tidak terlalu bebas keluar atau masuk.

Tobin Tax is an international tax on foreign exchange transactions. Ide pajak tersebut dimaksudkan untuk mendukung kebijakan ekonomi makro, salah satunya terkait krisis mata uang atau dengan kata lain, pajak atas transaksi valuta asing (valas) dirancang untuk melindungi fluktuasi nilai tukar mata uang. Adapun bahwa pajak tersebut berpotensi menambah penerimaan (a generator of revenue), itu hanya sebagai efek samping, bukan tujuan utama ${ }^{15}$.

Tujuan Tobin Tax ada dua. Pertama, mengurangi tindakan spekulatif penanam modal jangka pendek yang dapat menyebabkan terjadinya volatilitas nilai tukar mata uang. Pajak akan meningkatan ekspektasi dan risiko jangka panjang lebih kecil dibanding jangka pendek. Kedua, mempertahankan serta meningkatkan otonomi makroekonomi nasional dan kebijakan moneter suatu negara ${ }^{16}$. Dihubungkan dengan rezim kebijakan nilai tukar, Tobin Tax sama-sama membantu baik bagi rezim nilai tukar tetap (fixed) maupun nilai tukar mengambang (floating), bahkan di gabungan keduanya seperti nilai tukar mengambang terkendali ${ }^{17}$.

Pengenaan pajak ini sangat sederhana yaitu mengenakan pajak secara advalorem sebesar 0,1-0,5\% atas volume transaksi valas. Cara ini diyakini dapat meredam aksi spekulasi transaksi valas yang biasanya berlangsung dalam jangka pendek. Dalam perkembangannya, Tobin tax tidak hanya dikenakan pada transaksi valas namun juga pada transaksi saham dan obligasi. Selain itu, pajak ini menjadi bagian dari cara untuk meredam efek krisis keuangan global dari sisi

\footnotetext{
15 Haq, Mahbub UI, Inge Kaul, Isabellle Grunberg, The Tobin Tax, Prologue by James Tobin, Oxford University Press, New York, 1996

16 ibid.

17 ibid.
}

kebijakan fiskal berupa pemberlakukan pajak atas modal asing. Dan kemudian berkembang pula bahwa isunya tidak lagi hanya soal biaya krisis keuangan, namun juga menyinggung tentang upaya memerangi penggelapan pajak, kerahasiaan perbankan, hingga perbedaan tarif dan kawasan suaka pajak ${ }^{18}$.

Para pendukung kebijakan Tobin Tax meyakini kebijakan ini akan membantu menstabilkan mata uang dan suku bunga di tengah keterbatasan cadangan devisa. Sementara yang menolak, beranggapan Tobin Tax akan menghilangkan potensi keuntungan transaksi valas dan berpotensi mengurangi volume transaksi keuangan, memperlambat pertumbuhan ekonomi global, serta menghambat pembangunan dalam jangka panjang ${ }^{19}$. Berdasarkan studi terdahulu, ada yang memberikan bukti bahwa Tobin Tax efektif, namun di sisi lain tidak efektif, sebagaimana dua hasil studi pada Tabel 1.

Tabel 1

Hasil Studi terkait Tobin Tax

\begin{tabular}{|c|c|c|c|}
\hline No & Peneliti & Negara, Kebijakan & Hasil Penelitian \\
\hline 1. & $\begin{array}{l}\text { Akira } \\
\text { Ariyoshi, } \\
\text { et.al. } \\
(2000)\end{array}$ & $\begin{array}{l}\text { Brazil, Chile, Colombia, } \\
\text { Malaysia } \\
\text { - Pajak aliran masuk } \\
\text { (entrance tax) valas } \\
\text { tertentu dan } \\
\text { pinjaman LN } \\
\text { - } \text { Kombinasi pajak tak } \\
\text { langsung inflows dan } \\
\text { minimum stay } \\
\text { requirement direct } \\
\text { dan portfolio } \\
\text { investment tinggi } \\
\text { - Pengenaan tangka } \\
\text { bunga LN } \\
\text { pinjaman } \\
\text { berjangka <18 bulan } \\
\text { Larangan membeli } \\
\text { surat ebrharga bagi } \\
\text { non-resident, } \\
\text { pembatasan } \\
\text { external liabilities } \\
\text { perbankan untuk } \\
\text { non-trade. }\end{array}$ & $\begin{array}{l}\text { Kebijakan yang } \\
\text { diambil memberi } \\
\text { dampak: } \\
\text { - Apresiasi nilai } \\
\text { tukar } \\
\text { - Short-term } \\
\text { capital inflows } \\
\text { menurun } \\
\text { - CA balance } \\
\text { menurun } \\
\text { - Rasio FDI } \\
\text { terhadap GDP } \\
\text { meningkat } \\
\text { - Meningkatkan } \\
\text { otonomi bank } \\
\text { sentral }\end{array}$ \\
\hline 2. & $\begin{array}{l}\text { CME } \\
\text { Group, } \\
2010\end{array}$ & $\begin{array}{l}\text { Pasar Modal di USA } \\
\text { (New York stocks } \\
\text { market dan U.S futures } \\
\text { market), Japan, } \\
\text { Sweden, Taiwan, dan } \\
\text { United Kingdom. } \\
\text { - Interest Equalization } \\
\text { Tax (IET) on interest } \\
\text { payment to } \\
\text { foreigners (USA) } \\
\text { - Stocktransaction tax } \\
\text { (Japan) }\end{array}$ & $\begin{array}{l}\text { Pengenaan pajak } \\
\text { pada pasar modal } \\
\text { (Tobin tax) pada } \\
\text { negara-negara } \\
\text { tersebut } \\
\text { berdampak: } \\
\text { - diminished } \\
\text { liquidity } \\
\text { - Increased higher } \\
\text { volatility } \\
\text { - driving financial } \\
\text { business to } \\
\text { alternate } \\
\text { trading venues }\end{array}$ \\
\hline
\end{tabular}

${ }^{18}$ https://www.cnbcindonesia.com/opini/20180816200235-

14-29048/depresiasi-rupiah-dan-relevansi-tobin-tax, diakses 24 Januari 2019

19 ibid 


\begin{tabular}{|l|l|l|}
\hline & $\begin{array}{l}\text { - Securities Trasaction } \\
\text { Tax } \\
\text { (Sweden) 0.5\%-1\%, }\end{array}$ & $\begin{array}{l}\text { resulting insignificant } \\
\text { in } \\
\text { revenue } \\
\text { collections }\end{array}$ \\
\hline & $\begin{array}{l}\text { Tobin tax on futures } \\
\text { (Taiwan) }\end{array}$ & \\
$-\begin{array}{l}\text { Stamp duty on } \\
\text { purchase of equity } \\
\text { shares and } \\
\text { debentures (UK) }\end{array}$ & \\
\hline
\end{tabular}

Sumber: Akira Ariyoshi, et.al. (2000). "Capital Controls: Country Experiences with Their Use and Liberalization". IMF Occasional paper dan CME Group, (2010). "Impact of Tobin Taxes"

Selain itu, disajikan pula rangkuman dampak Tobin Tax terhadap volatilitas, likuiditas, penentuan harga, penerimaan pajak, dan dampak lainnya di pasar negara Swedia, Taiwan, USA, dan Jepang sebagaimana tersaji pada Tabel 2 .

Tabel 2

Dampak Tobin Tax terhadap Pasar

\begin{tabular}{|c|c|c|c|c|c|c|}
\hline & & \multicolumn{5}{|c|}{ Impact on } \\
\hline Study & $\begin{array}{l}\text { Market(s) } \\
\text { Examined }\end{array}$ & Volatility & Liquidity & $\begin{array}{c}\text { Price } \\
\text { Discovery }\end{array}$ & $\begin{array}{c}\text { Tax } \\
\text { Revenue }\end{array}$ & Other \\
\hline Campbell \& Froot (1993) & $\begin{array}{c}\text { Swedish stocks and } \\
\text { bonds }\end{array}$ & & $\downarrow$ & & $\downarrow$ & $\begin{array}{l}\text { Significant } \\
\text { expatriation of } \\
\text { trading activity }\end{array}$ \\
\hline Chou \& Lee (2002) & Taiwan futures & & $\downarrow$ & $\downarrow$ & & $\begin{array}{l}\text { Market migrated } \\
\text { to Singapore }\end{array}$ \\
\hline Chou and Wang (2006) & Taiwan futures & $\uparrow$ & $\downarrow$ & $\downarrow$ & $\downarrow$ & $\begin{array}{l}\text { Market migrated } \\
\text { to Singapore }\end{array}$ \\
\hline $\begin{array}{c}\text { Chung, Liu, Wu, Yang } \\
(2003)\end{array}$ & Taiwan futures & $\uparrow$ & $\downarrow$ & $\downarrow$ & $\downarrow$ & $\begin{array}{l}\text { Market migrated } \\
\text { to Singapore }\end{array}$ \\
\hline Edwards (1993) & U.S. futures & & $\downarrow$ & & $\downarrow$ & Market migrated \\
\hline Feldstein (1988) & NY Eurobond & & & & & $\begin{array}{c}\text { Market migrated } \\
\text { to Europe }\end{array}$ \\
\hline Greene (1969) & NY Eurobond & & & & & $\begin{array}{c}\text { Market migrated } \\
\text { to Europe }\end{array}$ \\
\hline $\begin{array}{c}\text { Habermeier \& Kirilenko } \\
\text { (2003) }\end{array}$ & Swedish stocks & $\uparrow$ & $\downarrow$ & & & $\begin{array}{l}\text { Market migrated } \\
\text { to London }\end{array}$ \\
\hline Нu (1998) & $\begin{array}{c}\text { Japan, Hong Kong, } \\
\text { Korea, Taiwan }\end{array}$ & $\begin{array}{l}\text { Incon- } \\
\text { clusive }\end{array}$ & $\begin{array}{l}\text { Incon- } \\
\text { clusive }\end{array}$ & & & \\
\hline Lui (2007) & Japanese stocks & & & $\downarrow$ & & \\
\hline OECD Study & U.S. FX Options & $\uparrow$ & & & & \\
\hline $\begin{array}{c}\text { Pollin, Baker \& Schaberg } \\
\text { (2003) }\end{array}$ & Theoretical & & & & $\uparrow$ & \\
\hline Saporta and Kan (1997) & UK stocks & No effect & & & & \\
\hline Shvedov (2004) & Japanese stocks & & & & $\begin{array}{l}\text { Temporary } \\
\text { success }\end{array}$ & $\begin{array}{c}\text { Market migrated } \\
\text { away from Japan, } \\
\text { other unintended } \\
\text { results }\end{array}$ \\
\hline Umlauf (1993) & Swedish stocks & $\uparrow$ & $\downarrow$ & $\downarrow$ & & $\begin{array}{l}\text { Market migrated } \\
\text { to London }\end{array}$ \\
\hline Wang \& Yau (2000) & U.S. futures & $\uparrow$ & $\downarrow$ & & & \\
\hline $\begin{array}{l}\text { Wang, Yau and Baptiste } \\
\text { (1997) }\end{array}$ & U.S. futures & $\uparrow$ & $\downarrow$ & & & \\
\hline
\end{tabular}

Sumber: CME Group, (2010). “Impact of Tobin Taxes”.

Di sisi lain, belum ditemukan hasil studi terkait insentif pajak untuk transaksi keuangan valuta asing sebagai Reverse Tobin Tax. Yang banyak tersedia terkait insentif pajak adalah studi berkenaan dengan pemberian insentif pajak pada penanaman modal langsung atau FDI yang populer dengan istilah tax holiday dan tax allowance.

\section{PEMBAHASAN}

\subsection{DATA FAKTA}

Gambar 4: Investasi Asing di Indonesia , 20132017

(dalam jutaan USD)

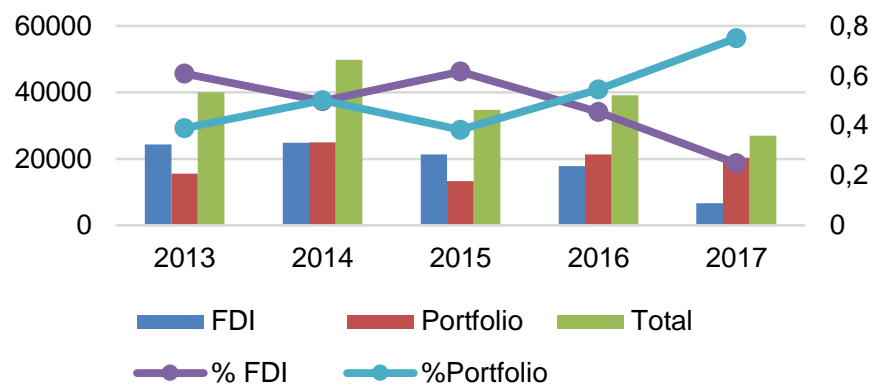

Sumber: www.ceicdata.com/ceicdata (diolah)

Berdasarkan statistik pasar modal yang dipublikasikan oleh Otoritas Jasa Keuangan (OJK), komposisi kepemilikan investor asing di efek berdenominasi rupiah rata-rata sebanyak $45 \%$ sedangkan sisanya adalah milik investor lokal. Sementara itu, kepemilikan asing di efek berdenominasi dollar amerika ternyata lebih tinggi yaitu rata-rata sebanyak $66 \%$ dan sisanya sebesar $44 \%$ dimiliki investor lokal. Lebih rinci, porsi kepemilikan efek di pasar modal Indonesia tersaji dalam Gambar 5.

Gambar 5: Komposisi Kepemilikan Efek di Pasar Modal Indonesia

Nopember 2018-Januari 2019 (dalam persen)

80

70

60

50

40

30

20

10

$-=\equiv \geq \underset{\substack{\mathbb{\pi} \\ \widetilde{\pi}}}{\mathbb{\widetilde { T }}}-=\equiv \geq \underset{\substack{\mathbb{\pi} \\ \widetilde{\pi}}}{\mathbb{\widetilde { \pi }}}$

Nopember 2018 Desember 2018 Januari 2019

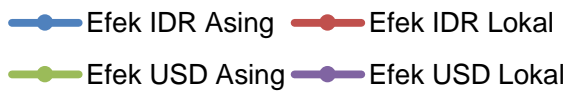

Sumber: https://ojk.go.id/id/kanal/pasar-modal/datadan-statistik/statistik-pasar-modal, diolah 
Selanjutnya, dilihat dari perkembangan Surat Berharga Negara (SBN) komposisi SBN Internasional dibanding SBN Domestik dari tahun 2010 s.d. 2018 (Nopember) masing-masing rata-rata sebesar $49 \%$ dibanding 51\%. Gambar 6 menyajikan rincian posisi SBN Indonesia berdasarkan jenisnya, dari tahun 2010 s.d. 2018 (Nopember). SBN yang dijual untuk pertama kali adalah penjualan di pasar primer, namun SBN juga dapat diperjualbelikan di pasar sekunder.

\section{Gambar 6: Posisi Surat Berharga Negara (SBN)} Indonesia menurut Jenis, 2010-2018

(Nopember), dalam juta USD

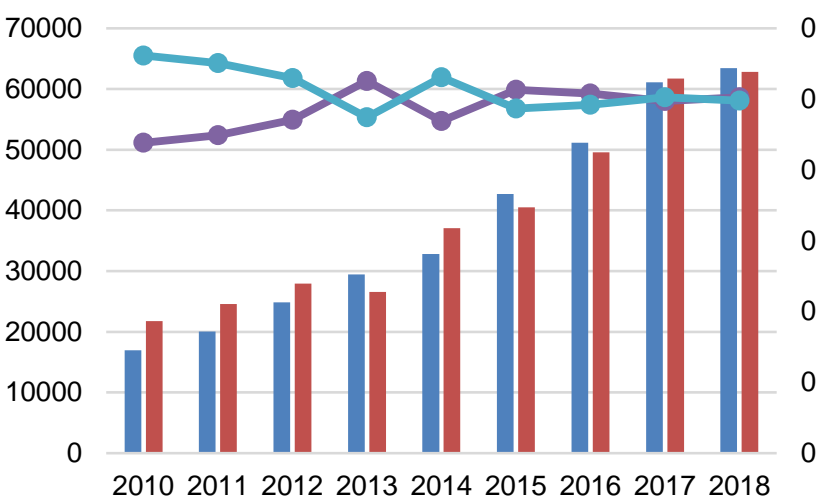

20112012201320142015201620172018

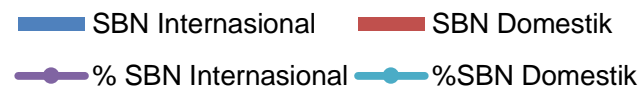

Sumber: Statistik Utang Luar Negeri Indonesia (SULNI), Bank Indonesia, Januari 2019, (diolah)

Dari gambaran di atas, nampak bahwa porsi investasi portfolio yang dimiliki oleh asing cukup besar. Di satu sisi hal ini menunjukkan investasi menarik bagi para investor asing, namun di satu sisi memunculkan ketergantungan dan potensi risiko terhadap perekonomian jika terjadi pengalihan modal tersebut ke luar Indonesia (capital outflow). Salah satu faktor yang menyebabkan investor asing tertarik menaruh modalnya di Indonesia adalah karena yield obligasi Indonesia dalam mata uang lokal dengan tenor 10 tahun mencapai $8,12 \%$, tertinggi dibanding negara lainnya di kawasan.

Ide Reverse Tobin Tax juga tidak terlepas dari isu akan berakhirnya masa tahan (holding period) dana repatriasi amnesti pajak sejumlah $\mathrm{Rp} 146,7$ triliun. Selain ini juga dihubungkan dengan proporsi harta berupa asset keuangan yang potensial untuk masuk ke pasar investasi di Indonesia. Dana repatriasi amnesti pajak sebesar Rp.146,7 triliun potensial untuk tetap berada di Indonesia, sedangkan deklarasi luar negeri sebesar Rp.1.036,76 triliun juga potensial jika masuk dalam bentuk investasi ke dalam negeri. Selanjutnya jika dilihat dari proporsi jenis harta utama yang dilaporkan dalam amnesti pajak, 58,5\% berupa asset keuangan (kas \& setara kas dan investasi \& surat berharga), yang terdiri dari Deklarasi luar negeri Rp805,9 triliun, repatriasi sebesar Rp109.2 triliun, dan deklarasi dalam negeri sebesar Rp2.093.1 triliun. Harta berupa asset keuangan tersebut utamanya yang dalam bentuk valas diperlukan untuk meningkatkan investasi di dalam negeri sekaligus dapat membantu menutup defisit transaksi berjalan (Laporan Tahunan DJP, 2017).

\subsection{ANALISIS}

Komposisi efek di pasar modal Indonesia didominasi investor asing. Rata-rata efek yang dimiliki asing baik yang berdenominasi mata uang Rupiah maupun mata uang asing sebanyak $56 \%$. Demikian pula obligasi yang diterbitkan pemerintah, kepemilikan asing di SBN tercatat di Rp 860,63 triliun setara dengan porsi $40,34 \%$ total surat utang yang dapat diperdagangkan ${ }^{20}$. Dengan kebijakan sistem devisa bebas yang dianut Indonesia, siapapun dapat memiliki valuta asing ataupun portofolio yang berdenominasi mata uang asing tanpa dibatasi. Juga sistem nilai tukar mengambang yang digunakan dalam kebijakan nilai tukar mata uang. Hal ini berdampak tingkat nilai tukar ditentukan oleh mekanisme permintaan dan penawaran di pasar. Kapan pun dan di mana pun, investor asing dapat dengan tiba-tiba (sudden reversal) menarik portofolionya di Indonesia.

Pengenaan pajak berupa Pajak Penghasilan (PPh) sebesar $0,1 \%$ dari jumlah bruto transaksi penjualan saham di Bursa Efek dilakukan oleh penyelenggaraan bursa efek melalui perantara pedagang efek pada saat pelunasan transaksi penjualan saham ${ }^{21}$. Mekanisme pengenaan pajak ini hampir mirip dengan Tobin Tax, namun pengenaan pajak ini tidak membedakan apakah saham dalam valuta asing atau rupiah. PPh $0,1 \%$ atas transaksi penjualan di bursa belum mampu menjaga arus investasi portofolio asing di Indonesia. Investor asing dapat dengan mudah memindahkan investasinya ke negara yang dianggap memberikan imbal hasil yang lebih tinggi. Indonesia hanya mendapatkan pendapatan dari pajak yang dikenakan atas transaksi penjualan di bursa. Transaksi harian di bursa efek per hari di tahun 2018 mencapai Rp8,5 triliun ${ }^{22}$. Apabila diambil rata-rata hari kerja dalam setahun sebanyak 260 hari, maka pendapatan PPh atas transaksi penjualan saham di bursa berkontribusi terhadap penerimaan pajak di tahun 2018 sebesar Rp2,21 triliun. Pendapatan pajak yang cukup besar namun belum bisa menahan investasi portofolio asing di Indonesia.

Berbeda halnya dengan saham, pengenaan pajak atas bunga obligasi yang dimiliki asing dikenakan PPh Pasal 26 dengan tarif $20 \%$ atau lebih rendah sesuai ketentuan tax treaty terhadap bunga atau diskonto

\footnotetext{
21 Keputusan Menteri Keuangan Nomor 282/KMK.04/1997 tentang Pelaksanaan Pemungutan Pajak Penghasilan atas Penghasilan dari Transaksi Penjualan Saham di Bursa Efek 22 IDX Statistics 2018
} 
obligasi. Jual-beli obligasi baik di pasar primer maupun sekunder tidak ada pemajakan seperti halnya penjualan saham. Untuk menarik investor asing dalam membeli obligasi pemerintah, pemerintah memberikan insentif berupa PPh Ditanggung Pemerintah atas bunga surat berharga negara (SBN) yang diterbitkan di pasar internasional. Kurun waktu 2017-2019 PPh Ditanggung Pemerintah atas bunga atau diskonto hasil penerbitan SBN tersebut rata-rata sejumlah Rp8,3 triliun, termasuk penghasilan jasa pihak ketiga ${ }^{23}$.

Hampir sama dengan pengenaan PPh atas bunga obligasi, pengenaan PPh atas bunga dari deposito dan tabungan serta diskonto Sertifikat Bank Indonesia (SBI) yang dimiliki asing dikenakan dengan tarif $20 \%$ atau lebih rendah sesuai ketentuan tax treaty. Belum ada insentif PPh final atas bunga deposito, tabungan, dan diskonto SBI yang dimiliki asing, hanya ketentuan tax treaty saja yang bisa menjadikan tarif lebih rendah. Insentif tarif PPh lebih rendah bahkan $0 \%$ hanya diberikan oleh pemerintah terhadap bunga dari deposito dalam mata uang dolar Amerika Serikat yang dananya bersumber dari Devisa Hasil Ekspor (DHE) dan ditempatkan di dalam negeri pada bank yang didirikan atau bertempat kedudukan di Indonesia atau cabang bank luar negeri di Indonesia. Tarif PPh final atas bunga dari deposito dan tabungan serta diskonto ini menjadi tarif $10 \%$ untuk jangka waktu penempatan satu bulan, tarif $7,5 \%$ untuk jangka waktu penempatan tiga bulan, tarif 2,5\% untuk jangka waktu penempatan 6 bulan, dan tarif $0 \%$ untuk jangka waktu penempatan lebih dari enam bulan ${ }^{24}$.

Kaitan dengan penerapan Tobin Tax terhadap investasi asing, sebaiknya difokuskan untuk stabilisasi nilai tukar dan tidak diperlakukan sebagai penerimaan semata. Tobin Tax ini diterapkan pada investasi yang jangka pendek. Tarif Tobin Tax berada pada kisaran tarif yang rendah, misalnya 0,01\%. Dengan Tobin Tax yang sangat rendah diharapkan tidak akan mengurangi daya tarik investor untuk menanamkan modalnya, sehingga kegiatan investor tetap berjalan seperti biasanya dan pemerintah masih mendapat keuntungan dari transaksi di pasar keuangan. Pertimbangan lain dalam penerapan Tobin Tax adalah apabila pajak ini hanya diberlakukan di Indonesia sendiri, dikhawatirkan akan terjadi pelarian modal keluar dan transaksi valas akan beralih ke negara lain yang tidak mengenakan pajak guna memburu imbal hasil yang lebih tinggi. Pasar gelap transaksi valas pun dikhawatirkan akan marak dan nilai tukar pun tidak dapat dikontrol dengan baik ${ }^{25}$.

Tambahan pajak berupa Tobin Tax atas transaksi penjualan saham di Bursa Efek, obligasi, maupun tabungan/deposito menjadikan pengenaan pajak berganda atas obyek yang sama, karena atas transaksi penjualan saham dan bunga obligasi/tabungan/deposito sudah dikenakan pemotongan/pemungutan PPh. Disamping itu, walaupun secara teoritis Tobin Tax dapat menahan spekulasi transaksi jangka pendek yang berakibat volatilitas nilai tukar, bukti empiris di pasar keuangan Swedia, Taiwan, USA, dan Jepang menyatakan bahwa Tobin Tax berefek investor bermigrasi ke negara-negara yang tidak mengenakan pajak atau pajaknya lebih rendah. Hal ini menjadikan pengenaan Tobin Tax kontraproduktif dengan tujuan pemerintah yang tidak ingin menghambat investasi asing yang masuk ke Indonesia.

Beberapa pengamat menyatakan bahwa saat ini tidak tepat untuk mengenakan Tobin Tax, yang lebih tepat adalah kebijakan RTT yang pada dasarnya adalah insentif pajak terhadap investasi portofolio asing agar investor asing lebih lama menahan modalnya di Indonesia dan tidak secara tiba-tiba mengalihkan ke negara asalnya atau negara yang dianggap lebih memberikan imbal hasil yang lebih tinggi. Namun demikian, pemberian insentif pajak ini sebagaimana disampaikan Menteri Keuangan Sri Mulyani, bukan ke masalah besaran insentifnya tetapi ke masalah bagaimana mendesain pemajakannya.

Kebijakan RTT berangkat dari konseptual Tobin Tax, dengan demikian insentif dalam skema RTT diberikan hanya terbatas pada investasi portofolio asing dengan tujuan mengurangi tindakan spekulatif investor jangka pendek yang dapat menyebabkan volatilitas nilai tukar mata uang. Seperti halnya Tobin Tax, kebijakan insentif pajak dalam RTT tidak diberikan terhadap investasi asing langsung (FDI).

Subjek Pajak yang diberikan insentif dalam RTT adalah investor asing yang melakukan investasi portofolio di Indonesia yang dapat berupa saham, obligasi, tabungan, deposito, maupun derivatif lainnya. Penentuan subjek pajak ini perlu dipertegas, apakah hanya dibatasi sebatas investor asing yang pemilik manfaatnya orang/badan asing yang berkedudukan bukan di Indonesia atau apakah yang sumber dananya berasal dari luar Indonesia tanpa melihat siapa pemilik manfaatnya. Penegasan ini perlu diatur agar jangan sampai insentif dalam RTT ini digunakan sebagai sarana untuk tax avoidance. Namun demikian, apabila hanya dibatasi Subjek Pajak Luar Negeri yang menerima, akan muncul isu tidak adanya equal treatment atau keadilan bagi investor dalam negeri. Terkesan pemerintah lebih berpihak kepada investor asing daripada investor dalam negeri.

Besaran insentif pajak dapat berupa pengurangan pajak atau pengenaan pajak yang lebih rendah sebagaimana halnya pengaturan DHE yang ditempatkan bank di dalam negeri dalam jangka waktu tertentu (holding period). Misalnya untuk saham yang diperdagangkan di bursa efek, dikenakan tarif PPh final yang lebih rendah dari $0,1 \%$ untuk masa holding period 1 bulan, 3 bulan, dan 6 bulan dengan tarif yang semakin rendah sesuai masa holding period yang semakin lama. Sama halnya dengan obligasi yang diterbitkan oleh pemerintah, akan dikenakan tarif pemotongan PPh atas 
bunga obligasi yang lebih rendah apabila tidak diperdagangkan sampai jangka waktu tertentu sejak pembelian pertama atau dari pembelian di pasar sekunder sampai dijual kembali. Untuk obligasi pemerintah ini, bagaimana insentif yang diberikan terhadap obligasi yang diterbitkan di pasar internasional. Sebagaimana dijelaskan di atas, obligasi pemerintah yang diterbitkan di pasar internasional, PPh atas bunganya mendapat insentif berupa fasilitas PPh Ditanggung Pemerintah. Asumsi tingkat suku bunga obligasi rata-rata di tahun 2017-2019 sebesar 7\% dan PPh atas bunga obligasi sebesar $20 \%$, dapat diperkirakan nilai obligasi pemerintah yang diterbitkan pemerintah di pasar internasional kurang lebih Rp600 triliun. Dan obligasi ini merupakan obligasi yang dapat diperdagangkan di pasar keuangan. Bentuk insentif apa yang bisa diberikan lagi terhadap obligasi pemerintah ini. Dan bagaimana membedakannya dengan obligasi yang diterbitkan bukan di pasar internasional.

Dilihat dari aliran transaksi antar jenis investor, juga perlu dipertimbangkan tidak semua aliran transaksi portofolio antara investor asing dengan investor dalam negeri. Aliran transaksi bisa terjadi antar sesama investor asing. Dalam skema RTT, mestinya yang mendapat insentif adalah transaksi penjualan portofolio dari investor asing ke investor dalam negeri yang sebelumnya telah melewati masa holding period. Dari sisi mekanisme pemberian insentif, pihak mana yang dapat ditunjuk oleh pemerintah untuk melakukan pencatatan masa holding period portofolio saham atau obligasi yang dipegang oleh investor asing. Pertanyaan berikutnya, bagaimana pemerintah mengawasi kepatuhan atas kebenaran pemberian insentif pajak atas portofolio ini.

Sulitnya menentukan subjek, objek, besaran insentif, mekanisme pemberian insentif pajak dalam $\mathrm{RTT}$, pengklasteran jenis portofolio investasi yang akan memperoleh insentif, dan pengawasan otoritas pajak kepatuhan pemenuhan kebenaran pemberian insentif, belum memungkinkan pemerintah memberikan insentif pajak terhadap portofolio asing yang masuk ke Indonesia. Fasilitas insentif pajak atas instrument portofolio asing saat ini sudah ada, berupa: PPh Ditanggung Pemerintah atas obligasi pemerintah yang diterbitkan di pasar internasional, pengurangan tarif pemotongan atas bunga deposito/tabungan sampai $0 \%$ terhadap hasil DHE yang ditanamkan di bank dalam negeri, juga subjek pajak luar negeri dapat memanfaatkan tarif lebih rendah sesuai Tax Treaty.

\section{SIMPULAN}

Saat ini porsi kepemilikan investasi portofolio oleh asing yang cukup besar di Indonesia, sehingga perlu dipikirkan penerapan kebijakan RTT dengan tujuan agar investasi tersebut bertahan lama di Indonesia. Kebijakan ini sejalan dengan kebijakan pemberian insentif perpajakan dalam rangka meingkatkan investasi. Namun demikian, penentuan teknis pengawasan jangka waktu investasi, utamanya di pasar sekunder harus dirumuskan sedetail mungkin termasuk antisipasi kemungkinan-kemungkinan perkembangan pasar. Administrasi perpajakan juga harus mampu melakukan pengawasan dan bisa membedakan arus uang/modal yang murni investasi portfolio dengan yang terkait transaksi terkait pertukaran barang dan jasa (ekspor impor). Otoritas perpajakan dapat mengoptimalkan peran pihak ketiga seperti perbankan, pasar modal, manajer investasi, OJK, BI, dan sebagainya. Selain itu diperlukan juga klaster bentuk investasi agar lebih mudah menentukan kriteria yang berhak mendapatkan Reverse Tobin Tax. Di sisi lain mungkin juga tidak perlu penerapan Reverse Tobin Tax terhadap bunga obligasi mengingat yield obligasi Indonesia yang tinggi dan insentif PPh ditanggung pemerintah bagi SBN di pasar internasional yang sudah merupakan bentuk 'insentif' bagi para investor. Dan perlu juga dipertimbangkan jangan sampai kebijakan ini terkesan keberpihakan negara hanya kepada pemilik modal asing.

\section{DAFTAR PUSTAKA}

Akira Ariyoshi, et.al. (2000). Capital Controls: Country Experiences with Their Use and Liberalization. Occasional Paper 190, International Monetary Fund.

Alika, Rizky (2018). Peringkat Layak Investasi Tanda Ekonomi Indonesia Baik. Katadata website: https://katadata.co.id/berita/2018/09/04/peringk at-layak-investasi-tanda-ekonomi-indonesia-baik

Alika, Rizky (2019). Ide Reverse Tobin Tax untuk Pertahankan Dana Asing ditanggapi Beragam. Katadata website: https://katadata.co.id/berita/ 2019/01/10/ide-reverse-tobin-tax-untuk-perta hankan-dana-asing-ditanggapi-beragam

Asmara, Chandra Gian (2019). Kajian Lagi, Sri Mulyani Pertimbangkan Tobin Tax Modal Asing. CNBC Indonesia website: https://www.cnbcindonesia. com/market/20190108161952-17-49601/kajianlagi-sri-mulyani-pertimbangkan-tobin-tax-modalasing

Basri, Muhammad Chatib (2019). This Time Is (Not) Different. Laman facebook akun Muhammad Chatib Basri Penuh / Kumparan website: https://kumparan.com/chatib-basri/this-time-isnot-different-1546936314603461846

Basri, Muhammad Chatib (2019). Muhammad Chatib Basri Membahas Kewaspadaan Terhadap Perekonomian Indonesia. Universitas Indonesia website: http://uiupdate.ui.ac.id/article/muham mad-chatib-basri-membahas-kewaspadaan-terha dap-perekonomian-indonesia

Bank Indonesia (2019). Indonesia's Balance of Payments and International Investment Position. Bank Indonesia website: https://www.bi.go.id/en/ publikasi/neraca-pemba yaran/Default.aspx 
Bursa Efek Indonesia (2018). IDX Statistics 2018. Jakarta: Bursa Efek Indonesia.

CEIC Data (2019). Indonesia Investasi Portofolio Asing. CEIC website: https://www.ceicdata.com/id/ indicator/indonesia/foreign-portfolio-investment

CME Group (2010). Impact of Tobin Taxes, Chicago: CME Group.

Djufri, Mohammad, (2018). Tinjauan Penerapan Tobin Tax Di Indonesi, Simposium Nasional Keuangan Negara (SNKN).

Direktorat Jenderal Pajak (2017). Laporan Tahunan DJP 2017. Jakarta: Direktorat Jenderal Pajak.

Hadiyantono, Tane (2019). Kepemilikan Asing di SBN Pecah Rekor. Penilai Harga Efek Indonesia website: http://www.ibpa.co.id/BeritadanPeristiwa/ArsipB erita/tabid/126/Entryld/7692/Kepemilikan-asingdi-SBN-pecah-rekor.aspx

International Monetary Fund (2015). Portofolio Investment. IMF Website: https://www.imf.org/ external/region/t/m/rr/pdf/Jan11.pdf

Kementerian Keuangan Republik Indonesia (1997). Keputusan Menteri Keuangan Nomor 282/KMK.04/1997 tentang Pelaksanaan Pemungutan Pajak Penghasilan atas Penghasilan dari Transaksi Penjualan Saham di Bursa Efek. Jakarta: Kementerian Keuangan Republik Indonesia

Nuryanto, Wahyu (2018). Depresiasi Rupiah dan Relevansi Tobin Tax. CNBC Indonesia website: https://www.cnbcindonesia.com/opini/20180816 200235-14-29048/depresiasi-rupiah-danrelevansi-tobin-tax

Olivia, Grace (2019). Tobin Tax Belum Cocok untuk Pasar Indonesia. Kontan website: https://nasional. kontan.co.id/news/tobin-tax-belum-cocok-untukpasar-indonesia

Pemerintah Republik Indonesia (2015). Peraturan Pemerintah Nomor 131 Tahun 2000 jo. Peraturan Pemerintah Nomor 123 Tahun 2015. Jakarta: Pemerintah Republik Indonesia.

Pemerintah Republik Indonesia (1997). Peraturan Pemerintah Nomor 41 Tahun 1994 Jo Peraturan Pemerintah Nomor 14 Tahun 1997 Tentang Pajak Penghasilan atas Penghasilan dari Transaksi Penjualan Saham di Bursa Efek. Jakarta: Pemerintah Republik Indonesia.
Prima, Benedicta (2019). Kebijakan reverse tobin tax masih dalam proses pengkajian. Kontan website: https://nasional.kontan.co.id/news/kebijakanreverse-tobin-tax-masih-dalam-proses-pengkajian

Putera, Andri Donnal (2018). BI: Rating BBB dari Fitch Tegaskan Indonesia Layak Investasi. Kompas website: https://ekonomi.kompas.com/read/ 2018/09/03/171242326/bi-rating-bbb-dari-fitchtegaskan-indonesia-layak-investasi

Republik Indonesia (2007). Undang Nomor 25 Tahun 2007 tentang Penanaman Modal Asing. Jakarta Republik Indonesia.

Republik Indonesia (1995). Undang-Undang 8 Tahun 1995 tentang Pasar Modal. Jakarta Republik Indonesia

Republik Indonesia (2002). Undang-Undang Nomor 24 Tahun 2002 tentang Surat Utang Negara. Jakarta Republik Indonesia.

Republik Indonesia (2008). Undang-Undang Nomor 7 Tahun 1983 sttd Undang-Undang No 36 Tahun 2008 tentang Pajak Penghasilan. Jakarta Republik Indonesia

Republik Indonesia (2016). Undang-Undang Nomor 18 Tahun 2016 tentang Anggaran Pendapatan dan Belanja Negara Tahun Anggaran 2017. Jakarta Republik Indonesia.

Republik Indonesia (2017). Undang-Undang Nomor 15 Tahun 2017 tentang Anggaran Pendapatan dan Belanja Negara Tahun Anggaran 2018. Jakarta: Republik Indonesia.

Republik Indonesia (2018). Undang-Undang Nomor 12 Tahun 2018 tentang Anggaran Pendapatan dan Belanja Negara Tahun Anggaran 2019. Jakarta: Republik Indonesia.

Setiawan, Sakina Rakhma Diah (2018). BI: Kenaikan Rating oleh Moody's, Prestasi Besar untuk Indonesia. Kompas website: https://ekonomi. kompas.com/read/2018/04/13/103000226/bi-kenaikan-rating-oleh-moody-s-prestasi-besaruntuk-indonesia

Sukmana, Yoga (2019). Sri Mulyani Dana Repatriasi Tak Lari ke Luar Negeri. Kompas website: https://ekonomi.kompas.com/read/2019/01/29/ 154854626/sri-mulyani-dana-repatriasi-tak-larilagi-ke-luar-negeri

Ul Haq, et.al (1996). Prologue by James Tobin, Tobin Tax Coping With Financial Volatility, Oxford University Press, New York. 